\title{
Aneurysm Tears Caused by an Aneurysm Clip Springing from the Clip Applier
}

\author{
Yasuo Murai, Kazutaka Shirokane, Takao Kitamura, Fumihiro Matano, Akio Morita
}

\begin{abstract}
We experienced two cases in which aneurysm clips sprang from the applier. In case 1, a subdural haematoma from a ruptured anterior cerebral artery aneurysm was detected. When the clip was opened for final positioning, it suddenly sprang from the applier and ruptured the aneurysm. In case 2, the clip suddenly sprang from the applier as the surgeon opened the applier to clip an unruptured anterior cerebral aneurysm. These accidental phenomena are rare but dangerous. We present these cases to help prevent similar occurrences in the future. Video recordings of actual procedures can point to potential mechanisms and help reduce the incidence of this complication.
\end{abstract}

RÉSUMÉ: Ruptures d'anévrisme causées par une pince projetée d'un applicateur. Nous avons fait l'expérience de deux cas au cours desquels des pinces (ou clips) utilisées pour ligaturer un anévrisme ont été projetées de leur applicateur. Dans le premier cas, on avait détecté un hématome sous-dural à partir d'une rupture d'anévrisme s'étant produite précédemment. Au moment d'ouvrir la pince en vue de sa mise en place définitive, celle-ci a été brusquement projetée de l'applicateur, ce qui a causé une rupture d'anévrisme. Dans le deuxième cas, la pince a été projetée de l'applicateur de façon inattendue tandis que le chirurgien ouvrait cet instrument pour ligaturer un anévrisme cérébral non-rompu détecté précédemment. Ces phénomènes imprévus sont à la fois rares et dangereux. Nous avons ainsi voulu présenter ces deux cas afin d'empêcher qu'ils ne se reproduisent à l'avenir. Des enregistrements vidéo d'interventions réelles pourraient faire ressortir les mécanismes potentiels en cause et nous aider à minimiser l'incidence de ce type de complication.

Keywords: cerebral aneurysm, clip, applier, rupture

doi:10.1017/cjn.2016.434

Can J Neurol Sci. 2017; 44: 326-328

Microsurgical cerebral aneurysm clipping is one treatment option for cerebral aneurysms, and particularly for those not responsive to intravascular treatment. ${ }^{1}$ Aneurysm clip appliers recommended by clip suppliers should be used for aneurysm clipping. ${ }^{2-4}$ The Yasargil aneurysm clip applier catalogue (Japanese version, B. Braun Aesculap Japan Co., Hongo, Japan) warns that incorrect appliers cannot grip the clip correctly, which may result in the clip being opened too widely. There are various clip manufacturers, and it is recommended ${ }^{3}$ that the correct applier be used for each manufacturer's clips.

Recently, we experienced two cases of aneurysm clips springing from the appropriate applier when held at the widest point, just prior to clipping. From an open state, the clips suddenly and forcefully closed, resulting in rupture of the aneurysms. In both cases, the intra-operative aneurysm rupture was successfully treated. Both patients were discharged without neurological deficit, and no abnormal findings were apparent on postoperative radiological imaging. To prevent similar events in the future, videos of the cases were studied, and the cause of this phenomenon was examined. Experienced neurosurgeons might not be familiar with such rare but serious surgical complications. We introduce this phenomenon as a surgical complication to promote awareness among neurosurgeons worldwide.

Case 1 (Supplemental Video). A 54-year-old man presented with headache. A left frontal/temporal subdural haematoma from the rupture of a left distal anterior cerebral artery (DACA) aneurysm and an unruptured right DACA aneurysm were detected using three-dimensional computed tomography angiography. The ruptured left DACA aneurysm was initially confirmed and clipped. The unruptured proximal right DACA aneurysm in the interhemispheric fissure was identified, and the aneurysmal neck was dissected. A Yasargil mini-clip applier and an FT 694 T clip were prepared for neck clipping. To confirm the appropriate clip position, a right-handed surgeon opened and closed the clip to place it in the appropriate position (Figure 1, left). When the surgeon had opened the clip sufficiently to position it, the clip suddenly sprang out of the clip applier. The clip abruptly occluded and ruptured the aneurysm. After haemostasis of the ruptured side using three temporary clips for the proximal and distal ACA, the ruptured aneurysm neck was closed with a 10-0 suture. Preservation of blood flow to the distal artery was verified using indocyanine green video angiography (ICGVAG). After the operation, no ischaemic change in the frontal cortex was apparent based on diffusion-weighted imaging on postoperative day 3 . Blood flow through the DACA was confirmed using cerebral angiography (Figure 1, right). The patient was discharged without neurological deficit.

Case 2 (Supplemental Video). A 6-mm unruptured anterior communicating artery (AcoA) aneurysm was detected using magnetic resonance (MR) angiography in a 48-year-old man during

From the Department of Neurological Surgery, Nippon Medical School, Tokyo, Japan (YM, KS, TK, FM, AM).

Received February 1, 2016. Final Revisions Submitted June 29, 2016. Date of ACCEPTANCE July 6, 2016.

Correspondence to: Yasuo Murai, Department of Neurological Surgery, Nippon Medical School, 1-1-5 Sendagi, Bunkyo-ku, Tokyo 113-86, Japan. Email: ymurai@ nms.ac.jp. 

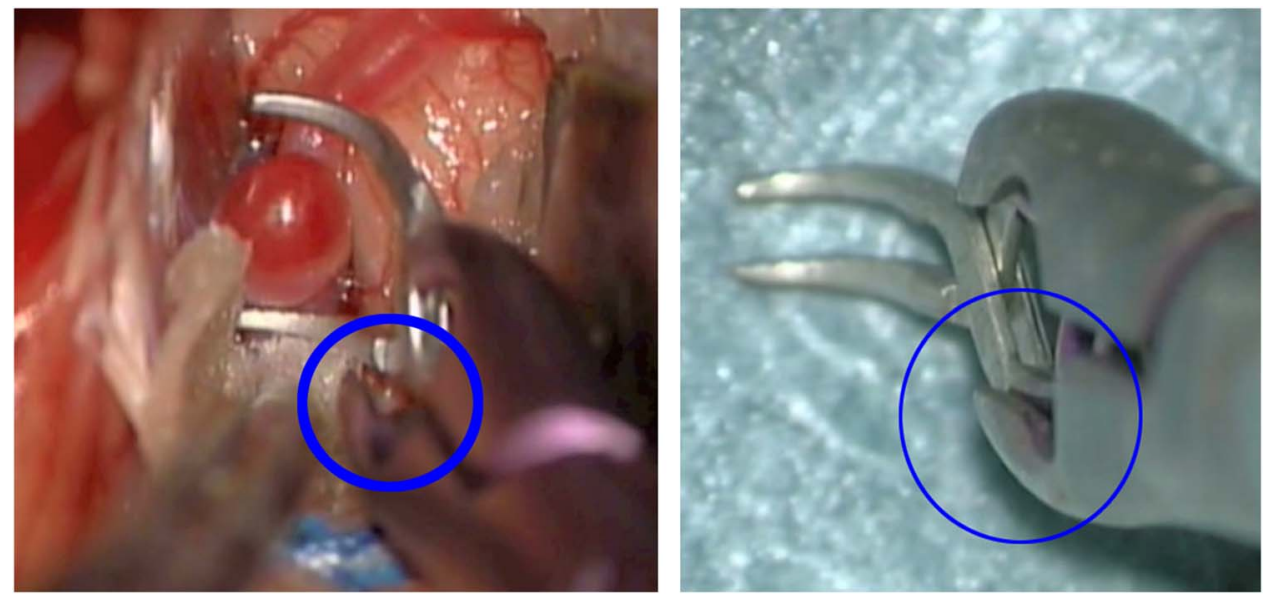

Figure 1: (Left) Intra-operative findings during aneurysm clipping. The proximal right distal anterior cerebral artery (DACA) aneurysm was in the interhemispheric fissure. It was identified, and the aneurysmal neck was dissected. An abnormal space was confirmed between the clip spring and the tip of the applier (blue circle). (Right) When correctly held, no space should exist between the clip head and applier (blue circle).

a check for headaches. A frontally projected AcoA aneurysm in the interhemispheric fissure was identified via an interhemispheric approach, and the aneurysmal neck, bilateral A2 segments and hypothalamic artery were dissected. A Yasargil standard clip applier and FT $742 \mathrm{~T}$ clip were prepared for neck clipping. To confirm the appropriate clip position, a right-handed surgeon opened and closed the clip. When the surgeon had opened the clip sufficiently for application in the final position (Figure 2. left), the clip suddenly sprang out and protruded from the applier (supplemental video). The clip abruptly occluded and ruptured the aneurysm. After point suction of the ruptured side, the ruptured aneurysm was clipped using an FT 742 T clip parallel to the neck side of the first clip. Preservation of blood flow to the distal artery and complete occlusion of the aneurysm were verified using ICGVAG. After the operation, no ischaemic change in the frontal cortex was apparent based on diffusion-weighted imaging and MR angiography on postoperative day 1 . The patient was discharged without neurological deficit.
We report herein our experience with two cases of aneurysm clips springing out from the appropriate clip applier as the clip was widely stretched just before placement. This is a dangerous phenomenon, and neurosurgeons should be aware of the risk.

In case 1 , the incident was caused by an incorrectly held aneurysm clip, as identified during replays of the intra-operative videos (see supplemental video and Figure 1). A space was present between the clip spring and the applier tip (Figure 1, left). When correctly held, no space should exist between the clip head and the applier (Figure 1, right).

In case 2, incorrect gripping was not identified (Figure 2) during review of the intra-operative video, but repeated opening and closing of the aneurysm clip took place during clip placement. Since the surgeon was grasping the clip applier in a downward manner (Figure 3, left) and repeatedly opening and closing the clip applier, the clip might have been pulled by gravity until it slipped out of alignment with the applier tip. This misalignment might be the cause
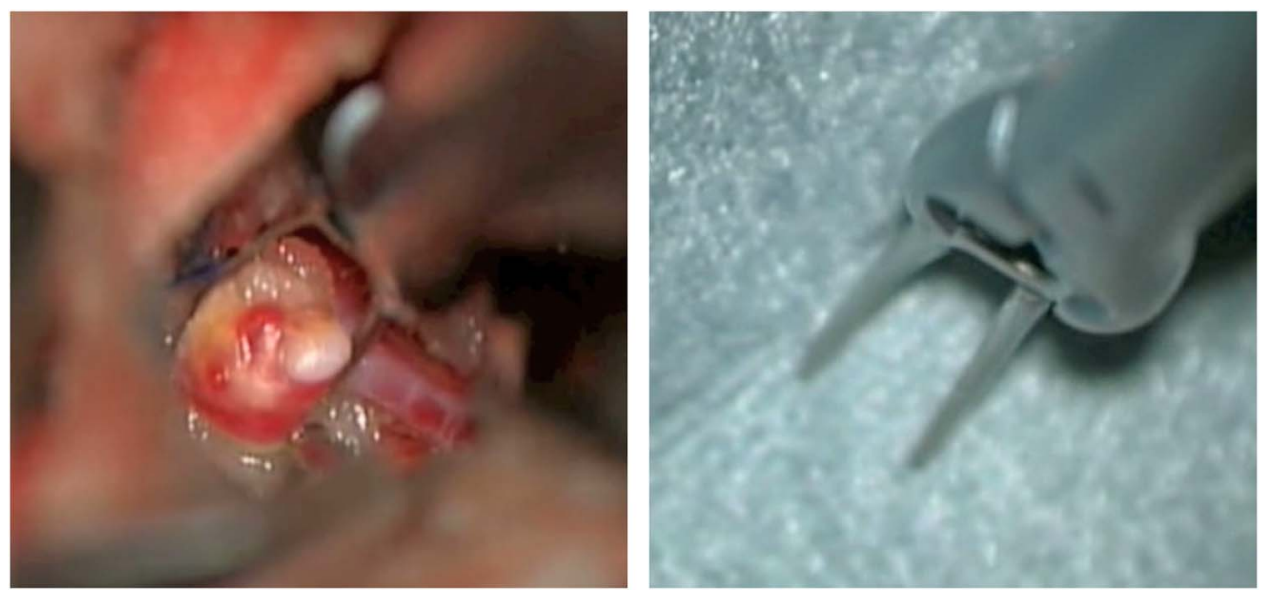

Figure 2: (Left) Intra-operative findings during aneurysm clipping in second case. An anterior communicating artery aneurysm in the interhemispheric fissure was identified. No abnormal space was confirmed between the clip spring and the tip of the applier. (Right) When correctly held, no space should exist between the clip head and applier. 

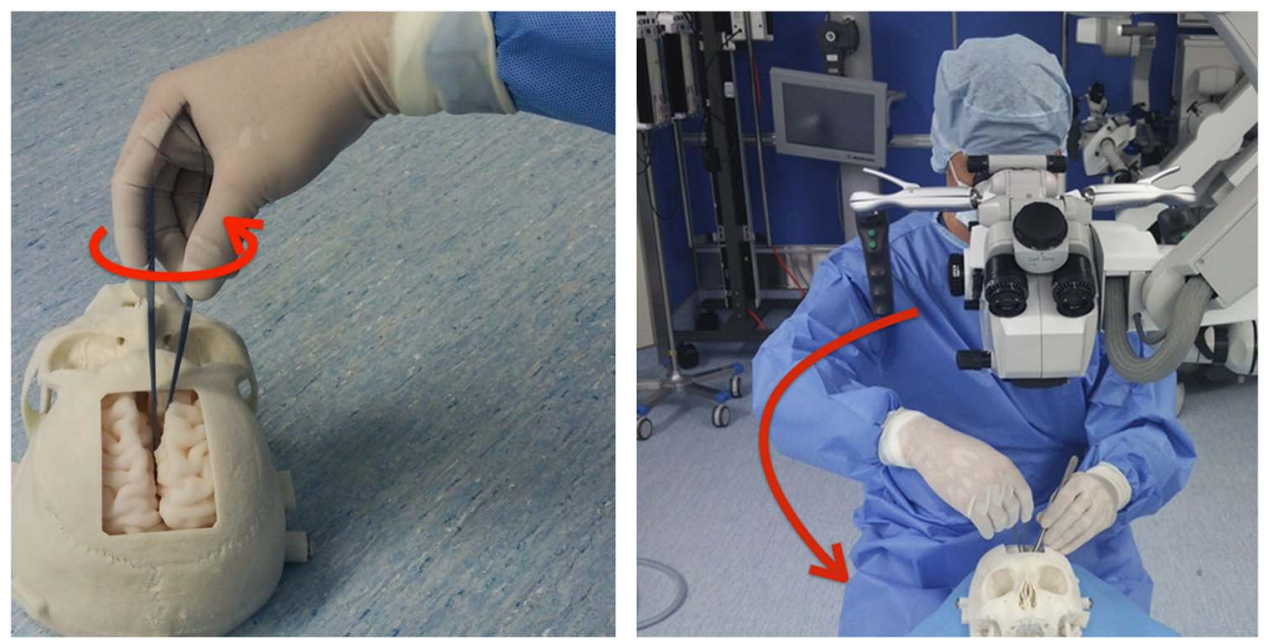

Figure 3: (Left) This picture shows the positional relationship between the surgeon's hand, clip applier and torque direction (red arrow). (Right) This picture indicates the surgeon's hand posture, the direction of the clip applier, and the patient's head position. This torque could have been reduced by the surgeon changing position to the right side (red arrow).

of ejection from the applier. This experience indicates that when the surgeon grasps the clip applier in a downward manner and repeatedly opens and closes the clip applier, care is required to ensure that the clip does not slip from the applier due to contact with surrounding tissues. In addition, some degree of torque in the clockwise direction (Figure 3, right) was placed upon the aneurysm clip applier as a result of the right-handed neurosurgeon using the applier. This torque could have been reduced by the surgeon changing position to the right side (Figure 3, right, red arrow). The clip applier in use was more than 10 years old and had been used in $\sim 700$ cases. The influence of wear and tear was also considered, but, according to the survey results of the manufacturer, there was no evidence of deterioration in the body of the clip applier. In the second case, there was no breakdown in the clip or applier, and the clip was held correctly, but there is a possibility that the manner of use caused the accident.

In both cases, the operator had had the experience of clipping more than 600 aneurysms. However, the operations presented here took place during the night and with an unfamiliar assistant. The medical staff's concentration may have been affected. Additionally, even with an appropriate clip applier, aneurysm clips that are incorrectly gripped do not fully open. ${ }^{1,2}$ The surgeon is required to assess whether the clips are incorrectly held by opening and closing the applier. A passage similar to the following is included in the Japanese version of the Yasargil aneurysm clip applier catalogue: "When you grip the clip incorrectly, there is a possibility that the clip may be damaged, or the clip may pop out from the applier, which is very dangerous." However, reports of such an occurrences have not previously been published.

During aneurysm clipping, incorrect gripping of the clip may cause it to spring from the applier. These accidental phenomena are rare but dangerous, and all neurosurgeons should be aware of the risk. The authors present these cases in the hope of preventing similar occurrences in the future. This is a high-risk phenomenon that can occur anywhere in the operating room. Neurosurgeons worldwide will hopefully benefit from these experiences.

\section{Disclosures}

Yasuo Murai, Kazutaka Shirokane, Takao Kitamura, Fumihiro Matano, and Akio Morita hereby state that they have nothing to disclose.

\section{SUPPLEMENTARY MATERIAL}

To view supplementary material for this article, please visit https://doi.org/10.1017/cjn.2016.434

\section{REFERENCES}

1. Zijlstra IA, Verbaan D, Majoie CB, Vandertop P, van den Berg R. Coiling and clipping of middle cerebral artery aneurysms: a systematic review on clinical and imaging outcome. J Neurointerv Surg. 2016;8(1):24-9. Epub ahead of print Nov 27, 2014.

2. Crockard HA, Koksel T, Watkin N. Transoral transclival clipping of anterior inferior cerebellar artery aneurysm using new rotating applier. Technical note. J Neurosurg. 1991;75(4): 483-5.

3. Dujovny M, Kossovsky N, Kossowsky R, Perlin A, Segal R, Diaz FG, et al. Intracranial clips: an examination of the devices used for aneurysm surgery. Neurosurgery. 1984;14(3): 257-67.

4. Krammer MJ, Lumenta CB. The new aneurysm clip system for particularly complex aneurysm surgery: technical note. Neurosurgery. 2010;66(6 Suppl Operative):336-8. 